\title{
LA DENUNCIA DE LAS REgLAS DE LA HAYA POR PARTE DEL ESTADO PERUANO: LA RESPONSABILIDAD CIVIL EN EL TRANSPORTE MARÍTIMO INTERNACIONAL DE MERCANCÍAS Y SU REGULACIÓN EN EL DERECHO MARÍTIMO CONVENCIONAL*
}

\author{
José Antonio Pejovés Macedo** \\ Universidad de Lima, Lima, Perú \\ Recibido: 19/11/2020 Aceptado: 1/12/2020 \\ doi: https://doi.org/10.26439/iusetpraxis2021.n053.5066
}

RESUMEN. El transporte marítimo moviliza aproximadamente el $80 \%$ del comercio internacional. Dada su importancia, en este artículo se analiza la responsabilidad del porteador en el transporte marítimo internacional de mercancías, a través de un acercamiento a los tres instrumentos internacionales que se ocupan del tema. Se examinan también las diferencias entre el contrato de transporte marítimo y el contrato de fletamento, y la situación en el Perú tras la denuncia de las Reglas de La Haya. Finalmente, se intenta identificar cuál es el régimen de responsabilidad que más le conviene al Perú.

PALABRAS CLAVE: Reglas de La Haya / Reglas de Hamburgo / contrato de transporte marítimo de mercancías / contrato de fletamento de buques

/ conocimiento de embarque

\footnotetext{
* Este artículo aborda el tema de la denuncia por parte del Estado peruano de las Reglas de La Haya, así como la responsabilidad del porteador en el transporte marítimo internacional de mercancías, a la luz de los convenios internacionales que regulan la materia. Se enmarca en una investigación auspiciada por el Instituto de Investigación Científica (IDIC) de la Universidad de Lima, que se realiza gracias a un concurso llevado a cabo a comienzos del 2020. El trabajo de investigación se titula Ventas marítimas en el comercio internacional: confluencia de la compraventa, el transporte marítimo, el seguro de carga y el crédito documentario, y culminó en marzo del 2021.

** Abogado por la Universidad de Lima. Magíster en Derecho Civil y Comercial por la Universidad Nacional Mayor de San Marcos. Profesor de la Facultad de Derecho de la Universidad de Lima. Socio del Estudio Pejovés, especializado en derecho marítimo.
} 


\section{THE DENUNCIATION OF THE HAGUE RULES BY THE PERUVIAN STATE: CIVIL LIABILITY IN THE INTERNATIONAL MARITIME TRANSPORT OF GOODS AND ITS REGULATION IN CONVENTIONAL MARITIME LAW}

ABSTRACT. The Peruvian State's denunciation of the Convention for the Unification of Certain Rules Relating to Bills of Lading (Brussels, 1924) has the effect that this international instrument, whose most important part is the regulation of the carrier's liability in the international maritime carriage of goods, will cease to be binding for Peru.

In this article, an analysis of the carrier's liability in the international maritime transport of goods is addressed, through an approach to the three international instruments that deal with the subject, given the importance of maritime transport, a mode through which approximately $80 \%$ of international trade is mobilized.

The differences between the contract of carriage by sea and the contract of affreightment are also analyzed, as well as the situation in Peru after the denunciation of the Hague Rules. Finally, an attempt is made to identify the liability regime that best suits Peru.

KEYWORDS: Hague Rules / Hamburg Rules / contract of carriage of goods by sea / contract of affreightment / bill of lading 


\section{INTRODUCCIÓN}

En primer lugar, quiero agradecer especialmente la invitación que recibí de nuestro decano, doctor Germán Ramírez-Gastón Ballón, para participar en esta edición especial de la revista lus et Praxis, que rinde homenaje a los primeros 40 años de creación de la Facultad de Derecho de la Universidad de Lima. Me honra doblemente, pues soy exalumno y profesor de la facultad.

Mediante el Decreto Supremo 012-2020-RE, publicado el 12 de mayo del 2020, el Estado peruano denunció el Convenio Internacional para la Unificación de Ciertas Reglas en Materia de Conocimientos de Embarque, suscrito en Bruselas el 25 de agosto de 1924 y conocido internacionalmente como las Reglas de La Haya. Como se sabe, el acto de denuncia implica que dicho instrumento internacional deja de ser vinculante para el Perú.

El referido Convenio de Bruselas de 1924 fue aprobado por el Perú mediante la Resolución Suprema 687 de 1964, y el instrumento de adhesión se depositó ante el Gobierno belga el 29 de octubre de ese año, con lo cual las Reglas de La Haya entraron en vigor para nuestro país el 26 de abril de 1965.

El porteador en el contrato de transporte marítimo de mercancías, que se documenta mediante conocimiento de embarque (bill of lading) o documento similar, se obliga a recibir las mercancías para su desplazamiento desde un puerto localizado en un Estado a otro puerto o lugar ubicado en otro Estado. Esa obligación de resultados supone que la carga que el porteador recibe en custodia debe conservarla y entregarla en el puerto de destino, a tiempo, al tenedor del documento facultado para recibirla. Cuando el naviero o porteador no cumple efectivamente con sus prestaciones, bien porque la carga se pierde totalmente, o llega averiada o con retraso, por culpa que le resulta atribuible, deberá responder por los daños causados y resarcir al titular de la carga.

La responsabilidad del porteador en el transporte marítimo internacional de mercancías es el punto central en las tres reglas que norman este tipo de transporte, y posee características singulares que la distinguen del régimen común de la responsabilidad civil. De ahí que se sostenga que estamos frente a un régimen especial de responsabilidad que con algunos elementos distintivos es regulado en los convenios internacionales relativos al transporte marítimo. Me refiero a las Reglas de La Haya y sus protocolos modificatorios de Visby (Bruselas, 1968) y de los Derechos Especiales de Giro (DEG) de 1979'; y al Convenio de las Naciones Unidas sobre el Transporte Marítimo de Mercancías (Hamburgo, 1978), mejor conocido como las Reglas de Hamburgo, convenios internacionales que se encuentran en vigor; así como al Convenio de las Naciones Unidas sobre el Contrato de Transportes Internacional de Mercancías Total o Parcialmente Marítimo (Nueva York, 2008), mejor conocido como las Reglas de Rotterdam.

1 El Perú no ha ratificado ni el Protocolo de Visby de 1968, ni el Protocolo de los DEG de 1979. 
En la elaboración de las Reglas de Hamburgo y de las Reglas de Rotterdam, tuvieron un rol destacado dos agencias formuladoras del sistema de Naciones Unidas: la Comisión de las Naciones Unidas para el Derecho Mercantil Internacional (UNCITRAL, por sus siglas en inglés) y la Conferencia de la Naciones Unidas sobre Comercio y Desarrollo (UNCTAD, por sus siglas en inglés). Cabe resaltar también el papel que cumplió un organismo internacional no gubernamental de especial relevancia en el derecho marítimo, el Comité Marítimo Internacional (CMI).

En este artículo se analiza la responsabilidad del porteador en el transporte marítimo internacional de mercancías a través de un acercamiento a los tres instrumentos internacionales que se ocupan del tema. Se examina también la situación en el Perú tras la denuncia de las Reglas de La Haya por el Gobierno peruano. Finalmente, una cuestión importante en relación con la responsabilidad en el transporte marítimo internacional de mercancías radica en intentar identificar cuál es el régimen de responsabilidad que más le conviene al Perú.

La alusión a las Reglas de Rotterdam es tangencial porque dicho instrumento internacional aún no se encuentra en vigor. Tras doce años de suscrito, hasta octubre del 2020 solamente cinco Estados lo han ratificado o han adherido, y son necesarios veinte actos de ratificación o de adhesión para que entre en vigencia.

\section{LOS DOS HEMISFERIOS EN LOS SERVICIOS DE TRANSPORTE MARÍTIMO}

Sobre los servicios de transporte marítimo, puede afirmarse - en sentido figurado- que se proveen o prestan en dos hemisferios bien acotados: el de los servicios regulares y el de los servicios no regulares. Esta diferencia se encuentra normada en los distintos ordenamientos jurídicos, es derecho marítimo público y tiene importancia en el otorgamiento de los títulos habilitantes para operar empresas navieras y explotar comercialmente buques mercantes. Para efectos de este trabajo y para comprender mejor la parte operativa relacionada con el transporte marítimo como negocio jurídico de derecho marítimo privado, conviene aproximarse a los principales elementos distintivos en la prestación de los servicios de transporte marítimo.

\section{Servicios regulares de transporte marítimo}

Los servicios regulares de transporte marítimo de mercancías, también conocidos como liners, se caracterizan por que intervienen líneas navieras que ponen buques a disposición de los usuarios con itinerarios y frecuencias preestablecidos para el traslado de mercancías.

Generalmente - aunque esta no es una afirmación absoluta-, estos servicios se asocian al transporte de carga heterogénea en contenedores, mediante buques que 
tengan las condiciones de navegabilidad para transportar este tipo de recipientes. Estos buques son de las clases que se conocen como portacontenedores, porque solo pueden trasladar contenedores, o multipropósito, porque pueden transportar diversos tipos de carga.

El servicio regular se relaciona usualmente con la celebración de contratos de transporte marítimo que se documentan con conocimientos de embarque (bill of ladings) o cartas de porte marítimo (sea waybills), que constituyen auténticos contratos de adhesión, pues no hay posibilidad de negociación entre las partes. Igualmente, se realiza el pago de fletes (el precio del servicio o contraprestación de los usuarios) preestablecidos, los cuales son de conocimiento público; y en los contratos se suelen insertar liner terms, que permiten distribuir costos y riesgos de ciertas operaciones conexas al transporte entre el porteador y el cargador, que son las partes celebrantes del contrato de transporte marítimo de mercancías.

El régimen de responsabilidad del porteador en los servicios de transporte marítimo liner es de carácter imperativo, con limitación de la deuda resarcitoria y está regulado en los convenios internacionales sobre transporte marítimo: las Reglas de La Haya de 1924, y sus protocolos de Visby de 1968 y de los DEG de 1979; las Reglas de Hamburgo de 1978, las Reglas de Rotterdam del 2008 (que aún no están vigentes); y los regímenes de países que no son parte de ningún instrumento internacional y aplican en esas relaciones jurídicas sus ordenamientos marítimos.

Este es el hemisferio de los common carriers, que disponen de instalaciones portuarias con un diseño especial -aunque también pueden operar en terminales portuarios polivalentes o multipropósito-y de equipos portuarios especializados para manipular contenedores, como grúas pórtico de muelle (portainers o ship to shore), grúas pórtico de patio (transtainers) o reach stackers, entre otros.

\section{Servicios no regulares de transporte marítimo}

Los servicios no regulares o irregulares de transporte marítimo de mercancías, también conocidos como tramps, se caracterizan por que las empresas navieras que prestan o proveen dichos servicios ponen a disposición de los usuarios buques sin frecuencias ni itinerarios preestablecidos, es decir, buques "vagabundos" o tramps, los cuales se fletan de acuerdo con la necesidad del usuario, bien por un tiempo o por un viaje o viajes determinados.

Generalmente - aunque esta tampoco es una afirmación absoluta-, los servicios no regulares están asociados al traslado de carga homogénea: graneles sólidos - limpios o alimenticios y sucios o industriales-y líquidos, mediante buques graneleros y tanqueros.

El servicio no regular usualmente se relaciona con la celebración de contratos de fletamento (charter parties): fletamento por tiempo (time charter) o fletamento por viaje 
(voyage charter), los cuales se documentan con pólizas o formularios de uso internacional. Las más conocidas son la póliza Baltime para los fletamentos por tiempo y la póliza Gencon para los fletamentos por viaje, ambas elaboradas y actualizadas por el Consejo Marítimo Internacional y del Báltico (BIMCO). Los contratos de fletamento son paritarios, en los cuales los términos y condiciones contractuales, incluido el precio del flete, son objeto de la negociación entre las partes; asimismo, en ellos se insertan gross terms, que permiten distribuir ciertos costos y riesgos de operaciones complementarias al fletamento entre el fletante y el fletador.

El régimen de responsabilidad del naviero o armador en los servicios tramp es de carácter dispositivo y no está contenido en ningún convenio internacional, sino en las leyes nacionales.

Este es el hemisferio de los private carriers, que disponen de instalaciones portuarias especializadas -o también terminales portuarios polivalentes-y de equipos portuarios especializados para manipular carga a granel, como, por ejemplo, cintas o fajas transportadoras, shiploaders y ductos submarinos.

\section{DIFERENCIAS ENTRE EL CONTRATO DE TRANSPORTE MARÍTIMO Y EL CONTRATO DE FLETAMENTO}

El contrato de transporte marítimo en régimen de conocimiento de embarque y los contratos de fletamento en sus distintos tipos: fletamento o arrendamiento a casco desnudo (bareboat charter), fletamento por tiempo (time charter) y fletamento por viaje (voyage charter), junto con otras figuras, son modalidades de los contratos de utilización o explotación de buques. El derecho marítimo ha desarrollado una teoría que explica la naturaleza y características de las distintas modalidades de utilización de buques.

Un sector de la doctrina señala que el fletamento es una modalidad del transporte; otro sector, a su vez, sostiene que el fletamento es un contrato mixto que participa del arrendamiento de cosas - entiéndase el buque (locatio rei) - y del transporte, entendido como la obligación de trasladar mercancías (locatio operis).

Nosotros seguimos la corriente doctrinaria que identifica el fletamento como un contrato autónomo e independiente, característico y especial del derecho marítimo. En este orden de ideas, de acuerdo con Arroyo (2001), las tres notas esenciales del contrato de fletamento son las siguientes:

a. La prestación principal del naviero es la puesta a disposición de un buque en condiciones de navegabilidad. Así pues, el buque y su disponibilidad, y no las mercancías o las personas, son el objeto del contrato. Un buque como elemento de un contrato de fletamento puede ser utilizado, por ejemplo, como un hotel flotante, para el tendido de cables submarinos, para realizar estudios 
oceanográficos, para levar cartas náuticas, para la navegación deportiva, para instalar un restaurante o un casino, etcétera.

b. El fletamento es una categoría genérica que abarca varias modalidades, según la disponibilidad del buque se vaya completando y sofisticando: desde un simple arrendamiento a casco desnudo, pasando por la obligación de navegar (fletamento en sentido estricto), hasta la obligación de transportar un bien en virtud de una póliza de fletamento (charter party) o de un conocimiento de embarque (bill of lading).

El buque y la navegación son los elementos fundamentales en torno a los cuales descansa la teoría de los contratos de utilización.

La distinción entre el fletamento o arrendamiento a casco desnudo, el fletamento por tiempo y el fletamento por viaje se basa en el grado de control respecto a la gestión del buque: (i) en el arrendamiento a casco desnudo, el arrendador o fletante desplaza íntegramente al arrendatario o fletador la gestión náutica y comercial; (ii) en el fletamento por tiempo, el fletante cede únicamente la gestión comercial; y (iii), en el fletamento por viaje, el fletante detenta la gestión náutica y comercial.

Correlativamente, el cuadro de derechos y obligaciones de cada parte varía en función de las facultades reservadas sobre el empleo del buque, ya sea comercial o náutico, por lo cual el fletante o el fletador es responsable frente a terceros de distinta manera, según la modalidad contractual de que se trate.

c. En tercer lugar, el fletamento y el transporte suelen ir unidos a dos modos distintos de explotación, documentación y régimen jurídico. Véase lo señalado en el apartado anterior de este artículo.

\section{LOS SISTEMAS DE RESPONSABILIDAD DEL PORTEADOR EN EL TRANSPORTE MARÍTIMO INTERNACIONAL DE MERCANCÍAS}

\section{Antecedentes históricos de la regulación de la responsabilidad del porteador}

La doctrina maritimista pone de relieve que hasta fines del siglo xIX los navieros 0 armadores, cuando actuaban como porteadores, conseguían eximirse de responsabilidad, aun cuando resultaba evidente y comprobable que por causas que les resultaban atribuibles habían incurrido en responsabilidad.

El antiguo libro III del Código de Comercio peruano de 1902, aún vigente, cuyas semejanzas con el derogado libro III del Código español de $1885^{2}$ resultan evidentes,

2 La Ley 14/2014, Ley de Navegación Marítima, que entró en vigencia el 25 de septiembre del 2014. derogó el libro III del Código de Comercio español. 
contiene normas de carácter supletorio que regulan el transporte por medio de la figura del capitán, a quien se le hace responsable del cuidado de la carga que tiene en custodia y cuya responsabilidad se exceptúa mediante la causales tradicionales: fuerza mayor, caso fortuito, culpa o negligencia del cargador y vicio propio de las mercancías. El Código de Comercio peruano, en la parte del comercio marítimo que todavía no ha sido "descodificada", está alineado con el principio de la libertad contractual o de la autonomía de la voluntad, y regula principalmente el contrato de fletamento por viaje, que incardina el transporte de mercancías, que era la modalidad usual de explotación de buques en los tiempos decimonónicos y desde antes.

El Código de Comercio peruano, como todos sobre los que gravitó el Código de Comercio francés de 1807, así como otros cuerpos normativos sobre los que no influyó la ley sustantiva mercantil francesa, no contiene normas imperativas (ius cogens) que regulen la responsabilidad del porteador que emerge del transporte marítimo de mercancías. Esta cuestión jurídica era común en la época en que los mares eran surcados por buques propulsados mediante la conjunción del viento y el velamen, y en los que regían y rigen los sistemas romano-germánico y del common law.

Se sabe que, al no existir normas inderogables para las partes que regulen la responsabilidad en el transporte marítimo de bienes, había descontento por parte de los cargadores, quienes muchas veces no encontraban el amparo legal necesario para defender sus intereses. De este modo, se entiende que las relaciones entre los porteadores y los dueños de la carga eran en alguna medida asimétricas, en detrimento de los intereses de los cargadores, pues los transportistas marítimos se valían de una serie de exoneraciones para eludir su responsabilidad frente a los daños causados a la carga que trasladaban.

Ray (1994a), con relación a la asimetría existente entre porteadores y cargadores antes apuntada, señala:

Ante la ausencia de disposiciones específicas y teniendo en cuenta que en el conocimiento se establecían las condiciones del transporte, las empresas, para reducir al mínimo su responsabilidad, fueron insertando cláusulas conocidas bajo la denominación de negligence clauses, que, impugnadas por los cargadores y consignatarios, los tribunales y parlamentos consideraron inválidas, por entender que traducían una imposición arbitraria del transportador. (p. 384)

El 13 de febrero de 1893 se sancionó en Estados Unidos la Harter Act, según la cual se declararon ilegales las cláusulas que tenían por fin exonerar al transportador de la debida diligencia para armar, equipar y aprovisionar el buque, es decir, ponerlo en condiciones de navegabilidad, así como todas aquellas que lo exoneraran por faltas cometidas al efectuar la carga, el arrumaje, el cuidado durante el viaje y durante la descarga de la mercadería. Expresamente se admitió la irresponsabilidad del transportador por las 
faltas cometidas por el capitán en la navegación y manejo (management) del buque y la limitación de su responsabilidad (Ray, 1994a, p. 384).

El uso exagerado de las cláusulas de exoneración se volvió más intenso a medida que las antiguas colonias se independizaron y se mostraron más débiles en su capacidad de negociación al ser países cargadores, principalmente exportadores de materias primas (Arroyo, 2001). Dichos excesos se producían en repúblicas jóvenes como el Perú, que no contaban con flotas de buques mercantes con capacidad para transportar la carga que se generaba.

En ese contexto, respecto a los antecedentes históricos de la regulación de la responsabilidad del porteador, Sánchez Calero (2000) sostiene:

La experiencia demostró en este sentido la necesidad de protección de los cargadores de mercancías en buques de línea que tenían una posición económica de hecho inferior a la de los porteadores, lo que había dado origen a un exceso de cláusulas de exoneración de responsabilidad por los daños o pérdidas de las mercancías, que los porteadores habían insertado en los conocimientos de embarque y que, en general, los derechos del siglo XIX no simplemente eran ineficaces para eliminarlas, sino que, inspirados en el respeto a la libertad contractual, en cierto modo las amparaban. Al mismo tiempo, debe tenerse en cuenta que, "como se ha recordado tantas veces", la revolución de la técnica de la navegación producida en ese siglo con la difusión de los buques de vapor y el desarrollo de las grandes compañías de navegación pusieron de manifiesto la exigencia de una nueva disciplina del transporte marítimo que se adaptara más a la realidad que las normas contenidas en los Códigos de esa época o en el derecho anglosajón. (p. 230)

Es meridianamente claro para la doctrina el uso masificado $-\mathrm{y}$ ciertamente desleal-que los navieros les dieron a las cláusulas de exoneración de responsabilidad. Fue ese uso desmesurado el detonante para arribar al ordenamiento en una cuestión tan sensible como la responsabilidad por los daños a la carga. En este orden de ideas, González-Lebrero (1998) plantea:

Respecto de las cláusulas de exoneración propiamente dichas, cabe expresar que ya había noticias concretas de ellas a fines del siglo xvIII, pues Balthazard Emerigon, en su libro sobre seguros y préstamos a la gruesa, escrito en 1783 , habla de las cláusulas que dit être, que significa que el cargador "ha dicho" que las mercancías son de tal calidad o cantidad, sin que el capitán lo haya verificado. Según tal estipulación, que el mencionado autor da como corriente en los contratos de la época, el capitán (transportista) no responde de la calidad interior, pero sí de las cantidades de bultos o bolsas. Las cláusulas fueron utilizadas por primera vez por armadores británicos a mediados del siglo pasado, generalizándose luego en los demás países, a tal punto que la cuestión de su implantación se estudió en el Congreso Marítimo de Amberes de 1885 primero, y en el de Bruselas de 1888 después. (p. 441) 
La citada Harter Act, que llevó el nombre de su proponente, el congresista estadounidense Michael Harter, tuvo resonancia y varios países la replicaron mediante la adopción de normas similares. Ray (1994a) menciona que "Nueva Zelandia en 1903 sancionó la Shipping \& Seamen Act; Australia en 1904 la Paramount Act; Canadá en 1910 la Canadian Water Carriage of Goods-Act; Japón en 1910 su Código de Comercio; Marruecos -colonia francesa-el Código de Comercio de 1919" (pp. 384-385).

La reacción de la comunidad marítima internacional frente a la necesidad de establecer un marco normativo que gobernara el transporte marítimo internacional, en concreto, lo concerniente a la responsabilidad del porteador, condujo a la celebración de conferencias internacionales con el objeto de aprobar reglas uniformes. Así, por impulso del Imperial Shipping Committee y de la International Law Association, se llevó a cabo en 1921 en La Haya la conferencia que supuso el inicio para la aprobación el 25 de agosto de 1924 del Convenio Internacional para la Unificación de Ciertas Reglas en Materia de Conocimientos de Embarque, universalmente conocido como las Reglas de La Haya.

La principal finalidad que tuvo la adopción de las Reglas de La Haya fue normar la responsabilidad de los porteadores por los daños a las mercancías, y así dejar atrás el statu quo consistente en la irresponsabilidad de los navieros mediante la incorporación de las cláusulas de exoneración; ello se consiguió a través de la negociación y el acuerdo de las partes en juego: los porteadores y los cargadores. Posteriormente, fórmulas similares, aunque con ciertos matices diferenciadores, han sido consagradas en las Reglas de Hamburgo ${ }^{3}$ y en las Reglas de Rotterdam.

\section{La responsabilidad civil del porteador en el transporte marítimo de mercancías}

La responsabilidad civil del porteador en el contrato de transporte marítimo internacional de mercancías en régimen de conocimiento de embarque ${ }^{4}$ posee un régimen especial que está desarrollado en convenios internacionales y en leyes nacionales integrantes del derecho marítimo. Además, tiene un punto de contacto con el derecho civil en lo que corresponde al régimen general de responsabilidad.

Cabe destacar el hecho de que, según la UNCTAD, aproximadamente el $80 \%$ del comercio internacional se moviliza por medio de buques - modo marítimo-, y un

3 Las Reglas de Hamburgo se originaron por iniciativa de la UNCTAD, que a su vez partió de una iniciativa del llamado Grupo de los 77, conformado, como se sabe, por países en desarrollo. Una de las razones que se tuvo en consideración para formularlas fue el hecho que las Reglas de La Haya se consideraban favorables a los intereses de los porteadores. La iniciativa de la UNCTAD fue materializada por UNCITRAL que para tal efecto, en 1969, creó un grupo de trabajo sobre reglamentación internacional del transporte marítimo.

4 Sobre la responsabilidad civil del porteador en el transporte marítimo de mercancías, nos hemos referido en otros lugares (Pejovés Macedo, 2006, 2007, 2019). 
promedio similar del comercio exterior peruano se traslada de la misma manera. En el transporte marítimo, como se mencionó anteriormente, se distingue el tráfico regular (liner) del tráfico no regular (tramp): el primero se identifica con el traslado de carga contenedorizada ${ }^{5}$ y de vehículos; mientras que el segundo, con el traslado de carga a granel. Sin embargo, es un hecho comprobable que, desde hace unos veinte años, las tendencias, como lo sugieren estudios especializados, registran un crecimiento sostenido del tráfico de contenedores, que está estrechamente vinculado con el transporte marítimo en régimen de conocimiento de embarque.

En un sentido amplio, la responsabilidad es, según Cabanellas (1986), “la obligación de reparar y satisfacer por uno mismo, o en ocasiones especiales por otro, la pérdida causada, el mal inferido o el daño originado" (p. 191). Por su parte, Ray (1996) recuerda:

En la primera página de la obra de los hermanos Mazeaud, publicada en 1957, con la colaboración del profesor de Grenoble, André Tunc, se nos dice que el término responsabilidad, de uso corriente hoy día, entró no hace mucho en nuestro lenguaje jurídico. Pothier lo empleaba excepcionalmente y la expresión habría sido tomada del derecho inglés por los filósofos del siglo XVIII, encontrándose en el Diccionario crítico de 1789 de Mr. Necker y el abate Feraud. (p. 4)

La responsabilidad del naviero en el Perú, que en el contrato de transporte marítimo de mercancías en régimen de conocimiento de embarque ${ }^{6}$ tiene la condición de porteador, se funda en la culpa o negligencia y está regulada por los artículos 600; 631, inciso 1; 632, y 633 del Código de Comercio; y, en el tráfico internacional, por la parte correspondiente de las Reglas de La Haya, que como explicaremos más adelante han sido denunciadas por el Estado peruano. Complementa ese desarrollo normativo especial el artículo 1314 del Código Civil, que dispone que "quien actúa con la diligencia ordinaria requerida no es imputable por la inejecución de la obligación o por su cumplimiento parcial, tardío o defectuoso".

Cabe recordar que, como ya se ha señalado, nuestro anacrónico libro III del Código de Comercio de 1902 contiene normas de carácter supletorio que regulan el transporte por medio de la figura del capitán, a quien se le hace responsable del cuidado de la carga que tiene en custodia y cuya responsabilidad se exceptúa por las causales tradicionales

5 Los contenedores trajeron una auténtica revolución que impactó notablemente en el transporte marítimo de mercancías. La masificación de su uso ha cambiado el panorama de la siniestralidad de bienes y ha generado cambios tecnológicos muy beneficiosos para el tráfico marítimo, los cuales van desde diseños de buques portacontenedores cada vez más grandes hasta cambios en las infraestructuras y equipamientos portuarios. Todo ello ha generado economías de escala muy favorables al comercio de bienes.

6 Para los alcances de este artículo, solo desarrollamos lo relativo a la responsabilidad del porteador en el transporte marítimo de mercancías. No se aborda la responsabilidad del porteador por el transporte de pasajeros y sus equipajes, la cual emerge del contrato de pasaje, ni la del fletante en los contratos de fletamento. 
de fuerza mayor, caso fortuito, culpa o negligencia del cargador y vicio propio de las mercancías. En la parte de comercio marítimo, el Código de Comercio peruano está alineado con el principio de la libertad contractual o de la autonomía de la voluntad, y regula principalmente el contrato de fletamento por viaje, que incluye el transporte de mercancías ${ }^{7}$. Como ya se ha indicado, no contiene normas imperativas (ius cogens) que regulen la responsabilidad del porteador en el transporte marítimo de mercancías.

El porteador en el contrato de transporte marítimo de mercancías, que se documenta mediante conocimiento de embarque (bill of lading) o documento similar, se obliga en virtud del contrato a recibir las mercancías para su desplazamiento desde un puerto a otro. Esa obligación de resultados supone que la carga que el porteador recibe en custodia debe conservarla y entregarla en el puerto de destino, a tiempo, al tenedor del documento facultado para recibirla.

\section{La responsabilidad del porteador en el derecho uniforme marítimo}

La alusión al derecho uniforme marítimo, o derecho convencional marítimo, tiene que ver con los convenios o convenciones internacionales que regulan aspectos relativos a instituciones o relaciones jurídicas propias del derecho marítimo. Para ser más precisos, a efectos de este trabajo, son solo aquellos convenios internacionales sobre transporte marítimo internacional de mercancías que forman parte de los convenios internacionales marítimos de carácter mercantil, formulados por la UNCTAD y por la UNCITRAL, en contraste con los convenios internacionales marítimos de carácter técnico formulados por la $\mathrm{OMI}$ y los de carácter laboral formulados por la Organización Internacional del Trabajo (OIT). Como bien señala Ray (1994b):

El tema de la responsabilidad del transportador es de fundamental importancia en el comercio exterior porque el transporte se encuentra en el centro de las transacciones comerciales, principalmente de las internacionales, y de ahí que la mayor parte de la labor realizada para la armonización del derecho comercial ha girado alrededor de la formulación de convenciones internacionales sobre transporte marítimo, aéreo y terrestre. (p. 7)

El régimen de responsabilidad adoptado en las convenciones internacionales sobre transporte marítimo de mercancías es el subjetivo, fundado en la culpa o negligencia, y

7 El contrato de fletamento por viaje (voyage charter) es una modalidad de los contratos de utilización o explotación de buques, junto con el contrato de fletamento por tiempo (time charter) y el arrendamiento o fletamento a casco desnudo (bareboat charter), por citar los principales y sin mencionar los contratos híbridos. En virtud del fletamento por viaje, el fletante pone a disposición del fletador un buque, total o parcialmente, para realizar uno o más viajes; el voyage charter no necesariamente se configura exclusivamente en la disposición del buque para desplazar o trasladar mercancías, ya que puede configurarse en la disposición del buque para realizar, por ejemplo, faenas de pesca, investigación científica, tendido de cables submarinos, entre otras actividades. 
tiene carácter imperativo, es decir, es inderogable para las partes. Cuando nos referimos a la responsabilidad subjetiva y objetiva o estricta como sistemas distintos, se asume que es responsabilidad subjetiva la fundada en la culpa o negligencia, y objetiva la que se basa en el riesgo y en la obligación de indemnizar, cuando se prueba la relación de causalidad entre el hecho y el daño, dejando de lado cualquier noción de culpa (Ray, 1994b).

En el transporte marítimo de mercancías, la responsabilidad del porteador es contractual, pues radica en un acuerdo de voluntades entre aquel y el dueño de la carga, y deriva del hecho de que el porteador inejecute el contrato de transporte marítimo o, de ejecutarlo, su prestación sea mal hecha. Al respecto, González-Lebrero (1998) sostiene:

La responsabilidad no puede ser sino contractual, y significa, en el orden práctico, que el transportista responde de los hechos resultantes de ese incumplimiento frente al cargador o destinatario, a quienes basta probar el contrato y el daño sobrevenido a sus bienes para hacerse indemnizar, con exclusión de toda consideración relativa a las causas de la inejecución. A su vez, el transportista debe probar, para eludir toda responsabilidad, que ha obrado sin culpa, es decir que su acción, aparentemente violatoria del contrato, se ha debido a causas extrañas que no se le pueden imputar. (pp. 437-438)

Esto señala la aceptación universal de la limitación de responsabilidad del naviero no solo en el transporte marítimo de mercancías, sino también en casi todas las relaciones jurídicas marítimas en las que participa utilizando buques. La responsabilidad limitada del naviero es un elemento distintivo del derecho marítimo, vinculado estrechamente con la reconocida especialidad de la materia y con el particularismo que antiguamente se atribuía a la disciplina, lo cual en la actualidad está puesto en cuestión por la doctrina.

Como se sabe, un objetivo de los especialistas, de las agencias formuladoras de las Naciones Unidas y de las organizaciones internacionales no gubernamentales relacionadas con el comercio y el transporte marítimo internacional es la uniformidad y armonización de las normas que regulan los intercambios comerciales y el tráfico marítimo internacional. Las bondades de la pretendida uniformidad son de alto calado y tienen que ver con la previsibilidad en la aplicación de las normas y la seguridad jurídica. Sin embargo, el panorama del derecho uniforme marítimo no es muy alentador si nos atenemos a la existencia de diversos regímenes de responsabilidad aplicables al porteador en el transporte marítimo internacional, como son los citados instrumentos internacionales: las Reglas de la Haya - sus protocolos de Visby y de los DEG-, las Reglas de Hamburgo y las Reglas de Rotterdam — que aún no han entrado en vigor-; así como al despliegue de sistemas de responsabilidad contenidos en leyes nacionales adoptadas por algunos países.

El grupo de trabajo que tuvo a su cargo la redacción del Proyecto de Ley de Navegación y Comercio Marítimo, constituido como parte de la Comisión Especial encargada de elaborar el Proyecto del Código de Comercio -creada mediante la Ley 26595-, de la 
cual fui integrante y que estuvo activa entre 1997 y el 2000, presentó un proyecto normativo que busca modernizar el derecho marítimo peruano, que como hemos mencionado sigue anclado en buena parte de su contenido en el libro III del Código de Comercio y en las Reglas de La Haya, que estarán vigentes en el Perú hasta el 1 de abril del 2022. cuando entren en vigencia las Reglas de Hamburgo. Sobre esta reforma, todavía inconclusa, pero que esperamos que llegue a buen término en beneficio del transporte y el comercio marítimo, nos hemos ocupado en otros lugares ${ }^{8}$. Como parte del proceso de modernización de nuestro derecho marítimo, sugerimos reemplazar las Reglas de La Haya por las Reglas de Hamburgo, instrumento más adecuado a la realidad y cuyo contenido es más técnico y moderno. Al respecto, Sánchez Calero (1981) indica:

Las Reglas de La Haya se redactaron en 1921, con la preocupación de elaborar un conocimiento de embarque-tipo, que sirviera para fijar un mínimo de protección a los cargadores. De ahí que se transcribieran en esas Reglas las cláusulas usuales de los conocimientos de entonces, eliminando aquellas que se estimaban inadecuadas. Las Reglas de Hamburgo, aun cuando siguen adoleciendo de un cierto casuismo, han mejorado extraordinariamente en su estilo con relación a las de La Haya. Si la redacción de estas fue una obra de prácticos, la de las de Hamburgo ha sido una labor de juristas, mucho más depurada y perfecta. (p. 23)

Las Reglas de Hamburgo son más equilibradas en cuanto a los intereses de los armadores y de los cargadores; es un conjunto de normas moderno, elaborado con mejor técnica y cuya aplicación práctica en los contratos no distorsiona el mercado, pues no influye a favor de ningún interés y solo cuida de racionalizar las transacciones entre cargadores y armadores, distribuyendo equilibradamente entre las partes los riesgos propios del transporte marítimo.

Ripert (1954), con relación a algunas debilidades de las Reglas de La Haya, explica:

Estas reglas, redactadas en inglés, se presentan como una especie de conocimiento tipo; contienen todas las cláusulas del contrato de transporte y comprenden, lo que es muy curioso, reglas sobre el ejercicio de la acción de responsabilidad, aunque el ejercicio de la acción no pueda depender evidentemente de la voluntad de las partes. Lo más sorprendente es que estas reglas convencionales agregaban que, fuera de las cláusulas expresamente permitidas por ellas, todas las demás cláusulas eran afectadas de nulidad [...]. Las Reglas de La Haya están redactadas, según la técnica inglesa, en artículos muy largos, divididos en párrafos y en letras del alfabeto, lo que hace incómodas las citas. Además, los mismos ingleses confesaron que, redactadas por hombres prácticos, estas reglas no son impecables desde el punto de vista jurídico. (p. 276)

8 Sobre la necesidad de reformar el derecho marítimo peruano y los alcances del Proyecto de Ley de Navegación y Comercio Marítimo, véase Pejovés Macedo (2008, 2007, 1999a, 1999b, 1998), así como “El Anteproyecto de la Ley General de la Navegación y del Comercio Marítimos" (1999). 
Conforme a lo comentado precedentemente, es oportuno resaltar la superioridad en técnica legislativa de las Reglas de Hamburgo frente a las Reglas de La Haya, lo cual es aseverado por la doctrina maritimista más autorizada, y que básicamente se manifiesta por el hecho que las Reglas de Hamburgo fueron elaboradas principalmente por abogados maritimistas conocedores de la materia, cuya ausencia fue por demás notoria en la redacción de las Reglas de La Haya.

Un dato relevante es el referido a la cercanía que tienen las Reglas de Hamburgo con el sistema romano-germánico, al cual está adscrito nuestro sistema jurídico. Este dato es importante para entender que naturalmente la aplicación de las Reglas de Hamburgo hará más eficiente la solución de controversias derivadas de la imputación de responsabilidad en el transporte marítimo, pues la sistemática latina adoptada por dichas reglas se presta mejor al encuentro de soluciones equitativas y comprensibles.

El hecho que las Reglas de Hamburgo contribuyan a una distribución más equilibrada de los riesgos entre el propietario de la carga y el porteador es trascendente, sobre todo en un país como el Perú, que es eminentemente cargador, en especial en el tráfico de línea. Y esto no se debería entender como un sesgo en perjuicio de los armadores, pues, como lo comprueba la realidad, en Chile las Reglas de Hamburgo están recogidas al menos desde 1988, y los navieros chilenos han desarrollado su actividad empresarial con singular éxito. Esa trascendencia se traduce fundamentalmente en quebrar el statu quo que significa mantener inequidades en cuanto a la distribución de los riesgos generados por el transporte marítimo. Ray (1996) con acierto ha dicho:

En la consideración del tema de la responsabilidad del transportador, debemos tener muy presentes los intereses económicos y, en especial, los de nuestros países, que son cargadores, es decir, exportadores e importadores de mercaderías, pero también con una loable pretensión de desarrollar sus flotas mercantes. (pp. 25-26)

\section{Elementos comunes en los distintos regímenes de responsabilidad contenidos en los convenios internacionales sobre transporte marítimo de mercancías}

Las Reglas de La Haya -y sus protocolos de Visby de 1968 y de los DEG de 1979-, las Reglas de Hamburgo y las Reglas de Rotterdam, como se ha señalado precedentemente, es como se conoce a los convenios internacionales que regulan el transporte marítimo internacional de mercancías. Estos instrumentos internacionales tienen en común entre ellos el desarrollo de la responsabilidad del porteador, institución fundamental por su relevancia en el transporte de mercancías por mar?.

9 Existen varios trabajos en los que se han comparado las Reglas de La Haya-Visby, las Reglas de Hamburgo y las Reglas de Rotterdam. Por todos, véase Berlingieri (2009). 
Como se indicó, dichos convenios internacionales o reglas se aplican al transporte marítimo de mercancías en servicios o tráficos regulares o liners - cuyas características aludimos anteriormente-, en los que se emiten conocimientos de embarque o documentos similares. Los convenios internacionales sobre transporte marítimo no se aplican a los contratos de fletamento de buques.

No abordaremos en este ensayo las relaciones existentes entre las pólizas de fletamento y los conocimientos de embarque, sobre todo si en aquellas se insertan cláusulas Paramount y en estos cláusulas de incorporación (incorporation clause), que en el primer caso remiten las controversias a alguna de las reglas mencionadas y en el segundo generan que muchas veces se entrecrucen los derechos y obligaciones de las distintas partes intervinientes en el doble juego de normas aplicables ${ }^{10}$.

Los elementos comunes que encontramos en los distintos regímenes de responsabilidad recogidos en los convenios internacionales sobre transporte marítimo de mercancías son los siguientes:

a. Internacionalidad de las reglas y su calidad de tratados

b. Carácter imperativo de las normas que regulan la responsabilidad del porteador

C. Responsabilidad subjetiva o fundada en la culpa

d. Responsabilidad limitada del porteador o limitación de la deuda resarcitoria

e. Régimen de la prueba e inversión de la carga en cabeza del porteador

f. Supuestos de incumplimiento que generan responsabilidad

g. Derogación de la responsabilidad del porteador en favor del titular de la carga

h. Periodo de responsabilidad

i. Prescripción de las acciones

Internacionalidad de las reglas y su calidad de tratados

Los convenios internacionales sobre transporte marítimo mencionados, que se conocen comúnmente como reglas, son instrumentos internacionales vinculantes para los Estados partes que expresan su intención de someterse a ellos mediante actos de ratificación o adhesión.

10 La cuestión es muy interesante y vinculada con el tema que se desarrolla; sin embargo, desborda los alcances de este ensayo. Al respecto, véase Arroyo (1993, pp. 429-501). 
La Convención de Viena sobre el Derecho de los Tratados de $1969^{11}$ estipula en su artículo 2, inciso 1-a), que "se entiende por tratado un acuerdo internacional celebrado por escrito entre Estados y regido por el derecho internacional, ya conste en un instrumento único o en dos o más instrumentos conexos y cualquiera que sea su denominación particular". Pinto-Bazurco (1997) define el tratado internacional de la siguiente manera:

Acuerdo entre sujetos del derecho internacional, ante todo entre Estados, en cuanto al establecimiento, cambio y terminación de sus derechos y deberes recíprocos en algún terreno (de la cooperación económica, política, científica, técnica, cultural, etc.). Es la fuente principal del derecho internacional. El término tratado internacional es un concepto genérico que abarca diversos tipos: acuerdo, pacto, convención, declaración, protocolo, etc. Cualquiera que sea su denominación, todos los tratados tienen igual fuerza jurídica. (p. 370)

Las Reglas de La Haya, de Hamburgo y de Rotterdam son convenios internacionales y en esta calificación son tratados que tienen efectos vinculantes para los Estados que son parte de ellos. Las tres reglas comparten el carácter de la internacionalidad. Como se desarrollará más adelante, La Haya y Hamburgo se encuentran vigentes en un número importante de países, mientras que las Reglas de Rotterdam todavía no han entrado en vigor.

\section{Carácter imperativo de las normas que regulan la responsabilidad del porteador}

Las normas que regulan la responsabilidad del porteador en el desplazamiento de las mercancías por el mar, en las tres reglas, son de carácter imperativo (ius cogens). Su carácter de derecho necesario impide que las partes puedan acordar su derogación en los contratos de transporte marítimo, salvo que se pacten obligaciones más gravosas para el porteador, como podría ser, por ejemplo, elevar el límite de la deuda resarcitoria del naviero en caso de que deba indemnizar por daños causados a la carga.

Como se sabe, las normas imperativas se denominan de esta forma por oposición a las llamadas normas dispositivas o supletorias, que se caracterizan por que las partes pueden prescindir de ellas en sus relaciones jurídicas. El carácter imperativo de las normas sobre la responsabilidad del porteador en el transporte marítimo de mercancías debe entenderse desde la óptica de lo que suponía antaño la irresponsabilidad del porteador, que ha sido aludida anteriormente. Con ese espíritu se aprobaron las Reglas de La Haya, y esa misma filosofía se hizo patente en las Reglas de Hamburgo y en las Reglas de Rotterdam.

11 Convención ratificada por el Perú mediante el Decreto Supremo 029-2000-RE, que entró en vigencia en el país el 14 de octubre del 2000. 
Emparanza Sobejano y Martín Osante (2010) recuerdan que en las Reglas de La Haya:

Se establece la nulidad radical de toda cláusula del contrato de transporte que pretenda exonerar o limitar la responsabilidad impuesta al porteador, pero admitiéndose la validez de las cláusulas que aumenten sus niveles de responsabilidad con respecto a lo previsto legalmente. Igualmente, se encuentran prohibidas todas aquellas cláusulas que intenten intervenir el onus probandi en cuanto a la realidad del daño, su causa y la presunción de responsabilidad. Del mismo modo, se entiende que están prohibidas las cláusulas que pretendan hacer perder el valor probatorio del conocimiento, las que acorten el plazo legal previsto para el ejercicio de las acciones de responsabilidad, etcétera. (p. 130)

\section{Responsabilidad subjetiva o fundada en la culpa}

El régimen especial de responsabilidad aplicable al porteador en el transporte internacional marítimo de mercancías, y consagrado en las tres reglas, es el subjetivo o fundado en la culpa, conforme se mencionó antes. Sin embargo, sobre este aspecto resulta oportuno citar opiniones autorizadas.

En todos los convenios sobre transporte de mercancías, el fundamento de la responsabilidad del porteador es la culpa. Las Reglas de La Haya-Visby establecen dicha norma en el artículo 4 (2) (q) al final de la lista de casos exceptuados, y como si fuera uno de ellos. La redacción de las Reglas de Hamburgo en el artículo 5 (1), por otro lado, es tan poco clara que fue necesario añadir al convenio un anexo de consenso, cuyo valor no está claro. En las Reglas de Rotterdam el principio de la responsabilidad por culpa está establecido en la primera disposición (segundo párrafo) del artículo 17, bajo el título "Fundamento de la responsabilidad", relativo a la prueba necesaria para exonerar al porteador de responsabilidad. (Berlingieri, 2012, p. 57)

Con relación al fundamento y al régimen de responsabilidad recogido en las Reglas de La Haya, Gabaldón García y Ruiz Soroa (2006) anotan:

El Convenio no contiene principio general alguno sobre la responsabilidad del armador, limitándose a establecer un largo catálogo de supuestos o casos exceptuados de tal responsabilidad. Sin embargo, de su análisis histórico y sistemático, se deduce que la responsabilidad del porteador se diseña y establece sobre el principio de responsabilidad por el incumplimiento culpable de sus obligaciones como tal porteador, es decir, de acuerdo con el esquema más generalizado en el derecho de los contratos. [...] De esta formulación se deduce que la responsabilidad del porteador se fundamenta en el incumplimiento culpable de sus obligaciones y que incluye, en principio, tanto las negligencias propias como las del personal auxiliar que emplea en el cumplimiento del contrato. Por otro lado, puede también afirmarse que de la conjugación de este precepto y de la cláusula general del art. 8. q) se deduce una presunción de responsabilidad contra el porteador, de forma que la carga de la prueba de que un daño a las mercancías acaecido durante el periodo de custodia se debe a una causa exceptuada de responsabilidad incumbe al porteador. (p. 581) 
En la misma línea, pero respecto de las Reglas de Hamburgo, Ray (1994) plantea: “(a) El sistema de la Convención de Hamburgo es de carácter subjetivo, fundado en la culpa, y desecha toda vinculación con el sistema de responsabilidad objetiva que está en vigencia en muy pocos sectores del derecho" (p. 13). Blas Simone (1980), en el mismo orden de ideas, apunta que "8. Las Reglas de Hamburgo estructuran el régimen de responsabilidad del porteador basado en el principio de su culpa o de la de sus agentes o dependientes" (p. 45). Asimismo, Berlingieri (1983) recuerda que cuando se redactaron las Reglas de Hamburgo, en el common understanding adoptado por la conferencia, se estableció que la responsabilidad del transportador está basada "en el principio de la culpa o negligencia presunta" y que el valor de dicha declaración fue solo el expresar la intención de quienes proyectaron las reglas incluidas en la convención (p. 60).

En lo que concierne a las Reglas de Rotterdam, Illescas Ortiz (2010), quien conoce de cerca el convenio porque presidió la UNCITRAL cuando este órgano de las Naciones Unidas se abocó a la revisión, negociación y aprobación del proyecto, señala:

La naturaleza jurídica de la responsabilidad del porteador se enraíza en dos características concretas: se trata de una responsabilidad por culpa o negligencia -no se trata, pues, de una responsabilidad objetiva o estricta-; también se trata de una responsabilidad solidaria para el caso [de] que dos o más personas resultaran responsables. (p. 1819)

\section{Responsabilidad limitada del porteador o limitación de la deuda resarcitoria}

Otro de los elementos comunes que se pueden apreciar en los convenios internacionales sobre transporte marítimo es el concerniente a la responsabilidad limitada del naviero en relación con el quantum de la deuda indemnizatoria. La responsabilidad limitada es una institución arraigada en el derecho marítimo, a la que en la actualidad no le faltan detractores y defensores.

El sistema de responsabilidad del porteador en el transporte marítimo de mercancías se complementa con la inclusión de límites de responsabilidad o limitación legal de la deuda de indemnización, cuya fijación es distinta en las tres reglas.

En el derecho común, la teoría general de la responsabilidad tiene como una de sus bases el resarcimiento total o integral (restitutio in integrum) a la víctima por el daño causado, de tal forma que la persona que padeció el evento dañoso obtenga una reparación que en lo posible retrotraiga la situación a su estado original o indemne. Sin embargo, el régimen general de responsabilidad no resulta aplicable en el derecho marítimo, porque este contiene reglas especiales propias de su autonomía, las cuales gobiernan una actividad también especial, como lo es la navegatoria.

La autonomía del derecho marítimo, y específicamente la naturaleza imperativa de las normas sobre responsabilidad del porteador en el transporte marítimo, conduce a que 
sus reglas sean las que razonablemente se apliquen a casos concretos, en defecto de las normas del derecho. Prima, pues, lo especial sobre lo general, lex specialis derogat generali.

La limitación de la deuda del porteador responsable - o los límites de responsabilidad - ha sido profusamente desarrollada por la doctrina, como bien destaca Sánchez Calero (2000):

Pero, aunque esta dicción esté autorizada por el uso, conviene señalar que se trata de una limitación de responsabilidad en sentido impropio, pues nos hallamos más bien ante un caso de limitación de deuda nacida de la responsabilidad del porteador. En efecto, el artículo 4.5 [se refiere al 4.5 de las Reglas de La Haya] no se ocupa de la limitación de la responsabilidad del porteador en el caso de incumplimiento de determinadas obligaciones, ni limita la responsabilidad del porteador a ciertos bienes de su patrimonio, sino que limita el importe de la deuda del porteador señalando que esta no puede exceder, en ciertos supuestos, de determinada cuantía, de manera tal que estamos ante un principio legal de la limitación de la deuda resarcitoria del porteador [...]. (pp. 406-407)

Sin caer en un exceso idealista, la limitación de la responsabilidad debería atender al justo equilibrio que debe existir para que las partes en un contrato de transporte marítimo documentado en un conocimiento de embarque u otro instrumento similar no vean insatisfechos sus intereses. Este equilibrio se evidencia en la supresión de la irresponsabilidad absoluta de los porteadores a cambio de permitirles poder determinar el costo de la deuda que les correspondería asumir en caso de que se produjera un siniestro que cause daños a la carga y que les resulte atribuible. De esa forma, se les facilita la información que les permite estructurar el precio del flete y de las primas de los seguros que corresponda contratar. El derecho a limitar la responsabilidad se pierde si el porteador actúa dolosamente.

El establecimiento de topes a la deuda del naviero ha facilitado el desarrollo del negocio armatorial, que tiene tanta importancia para el comercio interior y exterior de los países, pues, como se ha dicho repetidamente en este ensayo, la mayor cantidad de intercambios mercantiles se traslada por medio de buques. En esta línea, Alzueta (1977) considera que la limitación de la responsabilidad es uno de los pilares del ejercicio de la navegación y sostiene:

La limitación de la responsabilidad permite al explotador del vehículo navegatorio conocer exactamente hasta dónde se extiende la misma, lo cual facilita la contratación de seguros, ya que, de no existir límites, las primas serían sumamente elevadas y los transportadores - por ejemplo- se verían en la alternativa de no asegurarse, corriendo el riesgo de quedar en la ruina en caso de producirse un accidente de importancia, o bien constituir el seguro e imputar las primas al precio del transporte, con lo cual este llegaría a precios prohibitivos. La finalidad es proteger la navegación, que es considerada de interés general, y evitar que las empresas sucumban bajo el peso de elevadas indemnizaciones. Se trata de uno de los medios posibles para el equilibrio económico fundado en un principio de 
justicia y equidad, como podrían serlo el subsidio estatal o el aumento de las tarifas de los servicios. El interés lógico que tienen los usuarios del vehículo navegatorio en la permanencia del servicio impone como natural consecuencia la solución de su financiación colectiva. (pp. 77-78)

Las Reglas de La Haya establecen los límites de la deuda resarcitoria del portador por pérdidas o daños a las mercancías transportadas, en el numeral 5 del artículo $4^{12}$, que fue luego modificado por el artículo 2 del Protocolo de Visby de $1968^{13}$. Las Reglas de Hamburgo estipulan los límites de la deuda en el artículo $6^{14}$, y las Reglas de Rotterdam en los artículos 59 y $60^{15}$. Las tres reglas contienen fórmulas relativas a la pérdida del derecho del porteador a limitar su responsabilidad.

Para cerrar esta parte del trabajo, resulta oportuno reproducir algunas ideas de Ray (1994a), así como citas recogidas por él de otros connotados maritimistas, respecto a las cláusulas de limitación de responsabilidad del porteador:

André Gautier, en su obra sobre las cláusulas exonerativas o de irresponsabilidad en materia de transporte marítimo, dedica un pequeño apéndice a las cláusulas limitativas y dice que es muy difícil discutir su validez porque son verdaderas cláusulas penales que determinan convencionalmente el valor máximo de la mercadería.

Lefebvre d'Ovidio expresa que la función de las cláusulas limitativas es predeterminar convencionalmente el límite máximo de la indemnización, para el caso de responsabilidad por avería, pérdida o deterioro de las mercaderías.

Teniendo en cuenta que la obligación que asume el cargador frente al transportador, el pago del flete, se determina comúnmente en base a caracteres cuantitativos (volumen, peso, número de unidades, etc.), con independencia del valor de la mercadería, también las obligaciones del transportador deben determinarse sobre la base de una suma atribuida como valor máximo de la unidad de carga.

12 El límite es 100 libras esterlinas por bulto o unidad o el equivalente de esa suma en otra moneda, a no ser que la naturaleza y el valor de esas mercancías hayan sido declaradas por el embarcador.

13 El límite se establece en 10000 francos por bulto o unidad, o 30 francos por kilogramo de peso bruto de las mercaderías, si esta cantidad es mayor. Por franco debe entenderse una unidad consistente en 65,5 miligramos de oro del título de 900 milésimos fino.

14 El límite se establece en 835 unidades de cuenta por bulto o unidad de carga, o 2,5 unidades de cuenta por kilogramo de peso bruto si esta cantidad es mayor. Establece también una limitación de la deuda resarcitoria del porteador por retraso en la entrega. Por unidad de cuenta se entiende el derecho especial de giro, tal como ha sido definido por el Fondo Monetario Internacional.

15 El límite se establece en 875 unidades de cuenta por bulto u otra unidad de carga, o 3 unidades de cuenta por kilogramo de peso bruto de las mercancías si esta última cantidad es mayor. Establece también una limitación de la deuda resarcitoria del porteador por retraso en la entrega. Por unidad de cuenta se entiende el derecho especial de giro, tal como ha sido definido por el Fondo Monetario Internacional. 
Es evidente que si se quiere conservar el equilibrio entre las obligaciones asumidas por las partes contratantes, el flete y la responsabilidad eventual del transportador deben conservar una cierta relación. Si el flete se fija sobre la base del peso, volumen o valor medio de la mercadería a transportar, es razonable que la eventual indemnización, para el caso de pérdida o daño, no deba superar el valor medio tomado en cuenta al determinarse el flete. (pp. 469-470)

Régimen de la prueba e inversión de la carga en cabeza del porteador

La carga de la prueba (onus probandi) recae en quien está obligado a probar un determinado hecho ante la instancia que esté conociendo de un proceso. Es común que esa carga recaiga en el que rompe el estado de normalidad, por circunstancias que requieren el pronunciamiento de un tribunal arbitral, la judicatura o alguna entidad de la administración para dar solución a la controversia o al procedimiento administrativo. Esta obligación legal de probanza es la regla en el derecho procesal común.

Los autores de derecho marítimo suelen referirse a la inversión de la carga de la prueba en el sentido de que corresponde generalmente al demandado -naviero o porteador- exhibir los medios que demuestren y prueben que es irresponsable por los daños causados a las mercancías al haber actuado diligentemente, cuando se enfrenta a reclamaciones dirigidas por el embarcador o el titular de las mercancías transportadas.

Como veremos más adelante, las tres reglas contienen normas referidas a incumplimientos que implican responsabilidad, y es frente a dichas causales que el porteador debe probar que si no ha cumplido sus obligaciones contractuales se ha debido a circunstancias o actos que generan su exoneración de responsabilidad, lo cual establece una presunción de irresponsabilidad que el cargador estará obligado a destruir.

Como el sistema se basa en la culpa del porteador, es el cargador el que debe probar tanto el daño como la negligencia del porteador en virtud del principio general según el cual "incumbe la prueba de las obligaciones al que reclama su cumplimiento y la de su extinción al que la opone" (art. 1214 CC). Pero, en todo caso, el porteador se exonera de la responsabilidad por pérdida y avería de las mercancías cuando se prueba alguno de los "peligros exceptuados" o la ausencia de culpa del porteador y de sus dependientes. Ambos principios han de ser estudiados caso por caso, pues frente a lo que pudiera deducirse a primera vista su aplicación no es automática. (Arroyo, 2001, p. 538)

Chami (2010), sobre la inversión de la carga de la prueba, apunta:

En el contrato de transporte de mercaderías por agua, como también en el transporte multimodal y en todo contrato del derecho civil o comercial, ante el incumplimiento de las obligaciones contractuales del deudor, se genera una presunción de culpa en su contra. El acreedor no necesita probar de manera expresa la culpa, sino que - reiteramos- ella queda acreditada mediante presunciones. Es entonces el deudor, en este caso, el transportador, quien debe destruir 
la presunción simple de culpa. Lo hace probando alguna de las causales de exoneración previstas por la Ley de la Navegación o por la Convención de Bruselas de 1924. Este esquema ha permitido afirmar que se produce la mentada inversión de la carga de la prueba. No obstante ello, no hay tal inversión porque la carga de la prueba en el contrato de transporte es similar al régimen que impera en el ámbito contractual del derecho civil. (p. 554)

Es decir, la presunción legal de culpabilidad (iuris tantum) del porteador por los daños causados a las mercancías opera en el sentido de que el titular de los derechos sobre las mercancías está eximido de probar las causas del daño. Finalmente, como se sabe, es el juez o el árbitro quien valorará las pruebas aportadas durante el proceso. Chami (2010) acertadamente agrega:

Se afirma que la excepción al sistema de culpa presunta la constituyen las obligaciones del medio. En ellas, contrariamente a lo que ocurre en las obligaciones de resultado en las que se presenta la presunción de culpa, el acreedor debe acreditar que existió culpa del obligado. (p. 555)

Desde el 17 de octubre del 2000, cuando entró en vigencia la Ley 27287, Ley de Títulos Valores, en el Perú, quedaron derogados los artículos 356 y 357 del Código de Comercio de 1902, aplicables a la distribución de responsabilidad por daños y distribución de la carga de la prueba entre cargador y porteador, según las causas de fuerza mayor, vicio propio de las mercancías, negligencia o culpa del porteador.

\section{Supuestos de incumplimiento que generan responsabilidad}

En el estudio de la responsabilidad del porteador en el transporte marítimo internacional de mercancías, lo concerniente a los supuestos de incumplimiento que generan responsabilidad es de crucial importancia. Por eso, la doctrina maritimista, al abordar el análisis de la responsabilidad del transportista, dedica especial atención al asunto.

Las tres reglas contienen normas referidas a supuestos de incumplimiento que implican responsabilidad por culpa, y es frente a dichas causales que el porteador debe probar que si no ha cumplido sus obligaciones contractuales se ha debido a circunstancias o actos que generan su exoneración de responsabilidad y que también son regulados en las reglas. Estos supuestos de incumplimiento, comunes en las reglas, causados fundamentalmente por la falta de la debida diligencia del porteador para poner el buque en condiciones de navegabilidad, son las pérdidas, daños o averías de las mercancías.

El retraso en la entrega de las mercancías, como supuesto de incumplimiento, no consta regulado de forma expresa en las Reglas de La Haya, lo que no ha impedido que haya sido invocado en procesos de reclamaciones marítimas y que un sector de la doctrina sostenga que dicho incumplimiento encuadra en los supuestos de pérdida o daño. El vacío en el que incurren las Reglas de La Haya respecto al incumplimiento por 
retraso en la entrega de las mercancías relativiza su aplicación práctica y conduce a que los conocimientos de embarque sometidos a dichas reglas generalmente contengan estipulaciones de exoneración de responsabilidad del porteador. Es pertinente mencionar que las Reglas de Hamburgo y las Reglas de Rotterdam regulan expresamente en el caso de retraso la consecuente responsabilidad: las Reglas de Hamburgo en los artículos 5 y 6, y las Reglas de Rotterdam en el artículo 21.

Como ya se indicó, solo nos referimos a supuestos de incumplimiento del porteador como elementos comunes en las reglas. Sin embargo, conviene precisar que existen otros supuestos, aparte del retraso en la entrega de la carga, que no son comunes a las tres reglas; tal es el caso, por ejemplo, de que las Reglas de Hamburgo contengan normas relativas al incumplimiento y responsabilidad del porteador por el transporte de animales vivos, por el transporte indebido sobre cubierta y por incendios a bordo.

Con relación a las Reglas de La Haya, que como sabemos es el instrumento internacional más antiguo de los tres que estudiamos en este trabajo y que el Perú ha incorporado a su legislación, Gabaldón García y Ruiz Soroa (2006) señalan:

El Convenio (Reglas de La Haya) menciona, como supuestos fácticos que pueden generar una responsabilidad del porteador, únicamente los de pérdidas, daños o averías de las mercancías, términos que nos remiten en todo caso al supuesto de daños físicos sufridos por las mercancías, que incluyen la pérdida total, la pérdida parcial o las averías (incumplimiento de la obligación ex recepto). (p. 580)

Dichos supuestos, como se mencionó anteriormente, se repiten en las Reglas de Hamburgo y en las de Rotterdam.

El porteador responde por los daños a las mercancías transportadas, lo cual se materializa en tres supuestos específicos: pérdida, avería y retraso. El porteador responde cuando incumple sus obligaciones, principalmente la de trasladar las mercancías, actividad que se desglosa en la obligación de transportarlas al punto de destino en el plazo acordado y de entregárselas al consignatario en las mismas condiciones en que las recibió (obligación de custodia). De allí que el daño total o parcial -avería- y el retraso en la entrega sean supuestos de incumplimiento contractual por parte del porteador (Arroyo, 2001).

\section{Derogación de la responsabilidad del porteador en favor del titular de la carga}

En las tres reglas está normada la posibilidad de derogar convencionalmente la responsabilidad del porteador en favor del titular de la carga, agravando la responsabilidad de aquel. Dichas normas prohíben que la responsabilidad del porteador pueda disminuir en desmedro de los intereses de la carga.

Se asume que, en los contratos de transporte marítimo de mercancías documentados con conocimientos de embarque o documentos similares, la parte débil del contrato es el embarcador o cargador (shipper), aunque la realidad indica que existen 
relaciones jurídicas en las que ocurre lo contrario. Este tipo de contratos, como se indicó antes, tienen la naturaleza de los contratos predispuestos o de adhesión.

El numeral 5 del artículo 4 de las Reglas de la Haya, el numeral 4 del artículo 6 y el numeral 2 del artículo 23 de las Reglas de Hamburgo, y los literales a) y b) del numeral 1 del artículo 79 de las Reglas de Rotterdam coinciden en el mismo sentido: se podrá pactar una responsabilidad mayor del porteador, pero nunca menor a la establecida imperativamente.

A efectos de un mejor entendimiento de cómo se aplica esta derogación de la responsabilidad del porteador en favor del titular de la carga, recogemos unos comentarios de Martín Osante (2010) respecto a las Reglas de Rotterdam, los cuales pueden extrapolarse con pocos matices a las Reglas de La Haya y a las Reglas de Hamburgo. En este orden de ideas, dicho autor sostiene:

En lo que se refiere al porteador y a la parte ejecutante marítima, las obligaciones y la responsabilidad no pueden excluirse o limitarse, directa o indirectamente, mediante cláusulas o acuerdos entre las partes del contrato de transporte, ya que tales acuerdos o cláusulas serían nulas - art. 79.1.a) y b) RR-. Por tanto, la responsabilidad impuesta al porteador y a la parte ejecutante en las Reglas de Rotterdam presenta un carácter imperativo mínimo, de forma que las cláusulas insertas en los contratos de transporte que prevean una exclusión o una reducción de los niveles de responsabilidad por debajo de ese mínimo serán nulas. Ahora bien, a contrario, serán perfectamente válidas aquellas cláusulas que incrementen la responsabilidad del porteador o de una parte ejecutante marítima por encima de ese mínimo legal fijado en las Reglas de Rotterdam. (p. 281)

\section{Periodo de responsabilidad}

El periodo de responsabilidad del porteador, es decir, el ámbito temporal efectivo de las normas, está contemplado en las tres reglas, como veremos a continuación.

El inciso e) del artículo 1 de las Reglas de La Haya dispone que el "transporte marítimo abarca el tiempo transcurrido desde la carga de las mercancías a bordo del buque hasta su descarga del buque". Se entiende que este periodo es de "gancho a gancho". Las Reglas de Hamburgo, en el numeral 1 del artículo 4, estipulan que "la responsabilidad del porteador por las mercancías en virtud del presente Convenio abarca el periodo durante el cual las mercancías están bajo la custodia del porteador en el puerto de carga, durante el transporte y en el puerto de descarga". Resulta evidente que el periodo de responsabilidad en las Reglas de Hamburgo es más extenso, ya que comprende el lapso durante el cual las mercancías están bajo custodia del porteador. Como lo expresa Blas Simone (1980):

La adopción de un criterio distinto y, a todas luces, más lógico y constructivo que el admitido por la Convención de Bruselas sobre el periodo durante el cual sobreviene 
la responsabilidad del porteador lleva al Convenio de Hamburgo a la necesidad de fijarlo normativamente. Esta situación se refleja en el establecimiento de una unidad temporal durante cuyo transcurso la responsabilidad del transportador deviene inderogable. (p. 35)

El numeral 1 del artículo 12 de las Reglas de Rotterdam dispone que "el periodo de responsabilidad del porteador por las mercancías establecido en el presente Convenio comienza en el momento en que el porteador o una parte ejecutante reciba las mercancías para su transporte y termina en el momento de su entrega". Sobre estas normas, Martín Osante (2010) opina:

El periodo de responsabilidad establecido en las Reglas de Rotterdam es más amplio que el acogido en las Reglas de La Haya-Visby y en las Reglas de Hamburgo, al concebir el transporte de mercancías como un transporte "puerta a puerta" (maritime plus), extendiéndose así el periodo de responsabilidad a las fases no marítimas del transporte de mercancías (terrestre por carretera o por ferrocarril, aérea...), tanto portuarias como no portuarias, previas y posteriores a la fase marítima, lo que constituye una gran ventaja frente a sus precedentes, al uniformizar el régimen del transporte internacional de mercancías. Por otra parte, se admite al porteador el empleo de las cláusulas FIOS y similares a fin de exonerarse de responsabilidad, en contra de la postura mantenida al respecto por la jurisprudencia continental. (p. 283)

\section{Prescripción de las acciones}

Como es común en el derecho respecto a la prescripción de las acciones legales, las tres reglas contienen normas relativas al término de prescripción de las acciones conducentes a iniciar procesos de reclamaciones marítimas por pérdidas, daños o averías a las mercancías.

El penúltimo párrafo del numeral 6 del artículo 3 de las Reglas de La Haya dispone que el porteador y el buque estarán eximidos de toda responsabilidad por pérdidas o daños, a no ser que se inicie una acción dentro del plazo de un año a partir de la entrega de las mercancías o de la fecha en que hubiesen debido ser entregadas.

El artículo 20 de las Reglas de Hamburgo dispone que toda acción relativa al transporte de mercancías prescribe en el plazo de dos años, si no se ha iniciado un proceso judicial o arbitral. El término de prescripción comienza al día siguiente en que el porteador haya entregado las mercancías o parte de ellas, o en caso de que no se hayan entregado las mercancías, el último día en que debieran haberse entregado.

Las Reglas de Rotterdam, en su artículo 62, estipulan que no se podrá iniciar procedimiento judicial o arbitral alguno respecto de reclamaciones o controversias derivadas del incumplimiento de obligaciones establecidas en dichas reglas una vez transcurrido el plazo de dos años. 


\section{Algunas diferencias entre las Reglas de La Haya y las Reglas de Hamburgo. Las faltas o culpas náuticas}

Como se ha mencionado antes, el Perú ha denunciado las Reglas de La Haya y no es parte de los protocolos de Visby y de los DEG. Las Reglas de Hamburgo entraron en vigor en 1992 y las Reglas de Rotterdam todavía no han entrado en vigencia. Por esta razón, conviene hacer un acercamiento a las diferencias entre ambas reglas, que complementan lo analizado anteriormente y que de cierto modo permiten tener una posición mejor para determinar qué régimen de responsabilidad en el transporte marítimo internacional de mercancías es el más conveniente.

Como se señaló precedentemente, las Reglas de La Haya y las Reglas de Hamburgo comparten similitudes o algunos elementos en común, pero también contienen elementos que las diferencian. Las diferencias notorias entre el sistema de responsabilidad de las Reglas de La Haya y de las Reglas de Hamburgo, como se apuntó líneas atrás, radican principalmente en el traslado de algunos riesgos, que antes eran asumidos por el titular de la carga, al porteador, lo cual de alguna forma pretende equilibrar la distribución de riesgos y sus consecuencias entre las partes intervinientes en un contrato de transporte marítimo de mercancías. Entre esos riesgos, los más resaltantes tienen que ver con la supresión de la exoneración de responsabilidad del porteador en caso de culpas náuticas y con la modificación de la fórmula de exoneración en caso de incendio, mediante la inversión de la carga de la prueba en cabeza del demandante.

\section{Las faltas o culpas náuticas}

La supresión de la exoneración de responsabilidad del porteador por las denominadas faltas o culpas náuticas en las Reglas de Hamburgo, es decir, los errores en la navegación en que incurre la tripulación del buque o la negligencia en su manejo técnico, es acertada y constituye sin duda la nota distintiva más polémica y más evidente. La existencia de la exoneración de responsabilidad por faltas náuticas es un asunto que ha sido muy discutido y en el que los intereses armatoriales están en abierto desacuerdo con su supresión. El concepto de falta náutica es de antigua data y hay que unirlo a la negligence cause que se incluía frecuentemente en los conocimientos de embarque de fines del siglo XIX. Arroyo (1993) señala con prudente acierto "[...] que toda futura reglamentación que agrave, respecto del parámetro actual, la responsabilidad del naviero por actos de sus auxiliares contribuirá favorablemente a la prevención del daño" (p. 289).

Los avances alcanzados por la ciencia y la tecnología han facilitado enormemente la navegación marítima y la han tornado más segura. Basta constatar, por citar algunos ejemplos, la posibilidad de prever el estado del tiempo o de las mareas a través de los satélites, o el uso del sistema de posicionamiento global en la navegación. La imputación de responsabilidad a estas alturas no debiera diferir en cuanto a errores técnicos de operación en cualquier vehículo: buques, aeronaves o camiones, sobre todo si en la 
actualidad se dispone de tecnologías de información y comunicaciones que conectan a todas las industrias y permiten supervisar bien las operaciones. Por esta razón, exonerar de responsabilidad al porteador en el transporte marítimo por los errores o culpas náuticas de sus dependientes, a través de una responsabilidad vicaria o refleja, especial para él por su condición de porteador, configura un supuesto jurídico anacrónico y carente de sustento, pues lo sensato es aplicar el criterio común de la culpa in eligendo y de la culpa in vigilando, como ocurre en todas las actividades.

Sobre esta cuestión, Cornejo Fuller (2003) recuerda que “[...] había mayoría en Hamburgo para la supresión total de la irresponsabilidad por culpa náutica. Esta cuestión fue transada en pasillos o reuniones informales (the package deal)" (p. 248). Y acerca de lo mismo, Blas Simone (1980) añade: "En la Asamblea de UNCITRAL, reunida expresamente en mayo de 1976 para considerar el anteproyecto, se intentó incluir la culpa náutica como excepción de responsabilidad del porteador, que el anteproyecto no contenía, pero la moción fue rechazada" (p. 16).

\section{Algunas diferencias notables}

Sin la pretensión de exponer una relación exhaustiva de las diferencias existentes entre las Reglas de La Haya y las Reglas de Hamburgo, apuntamos las más notables:

1. El sistema responsabilidad de las Reglas de La Haya se fundamenta en la técnica casuística del sistema jurídico del common law o anglosajón, mientras que las Reglas de Hamburgo concuerdan con el sistema romano-germánico o continental, es decir, la fórmula genérica luego aplicada al caso concreto. Como es sabido, varios países de Europa continental y de Iberoamérica forman parte de la familia romano-germánica. En esta línea, las Reglas de Hamburgo eliminan la lista de diecisiete causales de exoneración (excepted perils) que puede invocar el porteador y las reemplazan por una formulación genérica.

2. El periodo de responsabilidad de las Reglas de Hamburgo abarca todo el tiempo transcurrido en que el porteador tiene a su cargo la custodia de las mercancías; en las Reglas de La Haya, el periodo se extiende solamente al tiempo que las mercancías se encuentran a bordo del buque, lo que se llama "gancho a gancho". Es decir, el periodo de responsabilidad en las Reglas de Hamburgo admite la posibilidad de ser más extenso para el porteador, situación que se presenta, por ejemplo, si el transporte incluye el desplazamiento hasta los almacenes del consignatario de la carga.

3. Como afirma Ray (1978):

La nueva fórmula de exoneración de las Reglas de Hamburgo eleva a principio general y en forma positiva el de ausencia de culpa que en la Convención de Bruselas figuraba como último eximente de responsabilidad del transportador 
(inc. q del art. 4). El transportador debe acreditar que adoptó "todas las medidas razonablemente requeribles para evitar el daño" porque si - a juicio del tribunalno se produce esa prueba, el transportador debe asumir las consecuencias de la avería, daño o de la demora que motivó el reclamo. (p. 11)

4. Las Reglas de Hamburgo obligan expresamente al porteador durante todo el tiempo que dure el viaje a mantener el buque en condiciones de navegabilidad (seaworthiness).

5. La responsabilidad por el retraso en la entrega de las mercancías o demora en la ejecución de la obligación de transporte no está prevista en forma expresa en las Reglas de La Haya. Las Reglas de Hamburgo regulan dicho supuesto en el literal b) del numeral 1 del artículo 6 .

6. Las Reglas de Hamburgo se refieren a la responsabilidad por la carga transportada sobre cubierta y al transporte de animales vivos, situaciones que no están contempladas en las Reglas de La Haya.

7. Las Reglas de Hamburgo prevén la responsabilidad del porteador contractual y del porteador efectivo. Las Reglas de La Haya solo se ocupan del porteador contractual y no necesariamente de la responsabilidad del porteador efectivo.

8. Como se mencionó anteriormente, existen diferencias en cuanto a la limitación de la deuda resarcitoria por parte del porteador.

\section{LAS REGLAS DE LA HAYA-VISBY Y LAS REGLAS DE HAMBURGO EN EL TRÁFICO MARÍTIMO DE AMÉRICA LATINA Y EL CARIBE}

Las Reglas de La Haya -y sus protocolos de modificación-y las Reglas de Hamburgo, como se ha repetido en este ensayo, se aplican en el transporte marítimo internacional de mercancías, especialmente en los servicios regulares que están directamente asociados al tráfico de carga que se consolida en contenedores, de allí la referencia al TEU como unidad de medida ${ }^{16}$.

En un evento virtual que se organizó en Lima en septiembre del 2020, se abordó el asunto de la denuncia de las Reglas de La Haya por parte del Gobierno peruano. Con el objeto de preparar mi breve presentación, revisé un estudio publicado el 10 de junio del 2020 por la Comisión Económica para América Latina y el Caribe (CEPAL) ${ }^{17}$, en el

16 TEU es un acrónimo que significa twenty foot equivalent unit o unidad equivalente a veinte pies. Se trata de una unidad de medida utilizada en el transporte marítimo de contenedores, es decir, en el tráfico marítimo de carga contenedorizada.

17 El estudio se titula La calma antes de la tormenta: comportamiento del movimiento de contenedores en los puertos de América Latina y el Caribe en 2019 y de los principales puertos durante los primeros meses de 2020, y fue elaborado por Ricardo J. Sánchez y Eliana P. Barleta. 
que aparece un cuadro que muestra en orden descendente los diez primeros países de América Latina y el Caribe que más TEU movilizaron durante el 2019. Este estudio técnico, enfocado en el movimiento de contenedores, permite ver cómo se reflejan las Reglas de La Haya-Visby y las Reglas de Hamburgo en el tráfico marítimo.

El orden de los diez países que en conjunto mueven 43,8 millones de TEU, es decir, el 81 \% del movimiento regional, según la CEPAL (2020), es como sigue: Brasil, Panamá, México, Chile, Colombia, Perú, Ecuador, República Dominicana, Argentina y Jamaica.

La página web Treaty Collection (https://www.treaties.un.org), administrada por las Naciones Unidas, registra el estado de los convenios internacionales, incluidos los marítimos. Según este portal, de esos diez países, Argentina, Ecuador, México y el Perú son Estados partes de las Reglas de La Haya. Cabe señalar que Ecuador ratificó el Protocolo de Visby de 1968; México ratificó el protocolo de 1979 sobre los DEG; y en el Perú las Reglas de La Haya tendrán vigencia hasta el 1 de abril del 2022, como se mencionó anteriormente. Jamaica aparece como Estado parte de las Reglas de La Haya en la web https://www.diplomatie.belgium, administrada por el Reino de Bélgica. En la citada web de las Naciones Unidas, también se puede ver que solo Chile y República Dominicana, de los diez países listados, son Estados partes de las Reglas de Hamburgo.

Brasil, Panamá y Colombia no son Estados partes de ningún instrumento internacional que regule el transporte marítimo internacional de mercancías. En estos países, las partes que intervienen en un contrato de transporte marítimo internacional de mercancías no tienen la obligación de insertar en los instrumentos que documentan esos contratos cláusulas Paramount que remitan a las Reglas de La Haya-Visby o a las Reglas de Hamburgo.

Si vemos los números del cuadro de la CEPAL (2020), se tiene que 22,1 millones de TEU en la región se movilizan en países que no son parte de ningún instrumento internacional; 6,3 millones de TEU que corresponden a Chile y República Dominicana se mueven bajo las Reglas de Hamburgo; 6,1 millones de TEU correspondientes a Argentina, Jamaica y el Perú se movilizan con el marco de las Reglas de La Haya, número que disminuirá cuando en nuestro país se dejen de aplicar estas reglas en el 2022; y 2,1 millones de TEU de Ecuador bajo las Reglas de La Haya-Visby.

El viejo anhelo del Comité Marítimo Internacional (CMI) de uniformar las normas de derecho marítimo en el mundo está lejano al menos si vemos la foto de la región. Esa pretendida uniformización, que parte del criterio básico: "a iguales problemas iguales soluciones", busca dotar al sector marítimo de normas predictibles que permitan reducir al mínimo posible la inseguridad jurídica que supone coexistir con distintos regímenes de responsabilidad contenidos en diferentes instrumentos internacionales y normas nacionales. Me refiero a la responsabilidad porque, como lo hemos reiterado, en todos los instrumentos internacionales relativos al transporte esta es la parte medular, 
instrumentos en los que la regulación radica en cómo se deben distribuir los costos y riesgos asociados al transporte entre el embarcador y el transportista o porteador.

Sería muy conveniente que al menos los países de Sudamérica contaran con normas de transporte marítimo internacional uniformes y que favorezcan a sus intereses generales. Es conocida la situación poco alentadora de la costa oeste de América del Sur cuando se tiene, si miramos sus puertos más representativos, que en Valparaíso se aplican las Reglas de Hamburgo, en el Callao las Reglas de La Haya, en Guayaquil las Reglas de La Haya-Visby y en Buenaventura ninguna de ellas.

Es válido preguntarse: ¿cuánto les cuesta a los países de la región tener esa dispersión normativa en el transporte marítimo internacional? Ojalá alguna vez desde la economía se haga el esfuerzo de medir y analizar cómo la incertidumbre jurídica impacta en los costos de transacción asociados al transporte marítimo y, por consiguiente, al comercio internacional. Los abogados maritimistas sabemos empíricamente que sí hay un impacto de calado.

\section{LAS REGLAS DE LA HAYA EN LA JURISPRUDENCIA PERUANA}

Las Reglas de La Haya, como es natural, han sido objeto de aplicación en muchos contratos de transporte marítimo internacional de mercancías en el Perú. En consecuencia, sus normas han sido invocadas por litigantes y recogidas en pronunciamientos que han puesto fin a controversias marítimas, bien sea por la justicia ordinaria o por la arbitral.

En el plano internacional existe abundante jurisprudencia en la que distintos tribunales han aplicado las Reglas de la Haya, con lo cual en su interpretación han aclarado muchos aspectos, especialmente respecto a la responsabilidad del porteador. Por su antigüedad y por la cantidad de Estados que son parte de dichas reglas, es lógico que haya más jurisprudencia en torno a las Reglas de La Haya y su Protocolo de Visby que la relacionada con las Reglas de Hamburgo; sin embargo, estas reglas también han sido aplicadas por diversos tribunales cuando han resuelto disputas marítimas ${ }^{18}$.

De la numerosa jurisprudencia existente en el Perú en la que se invocan las Reglas de La Haya, presentamos algunas sentencias de casación dictadas en los últimos años:

1. En la Casación 3331-2013-Callao (Pacífico Peruano Suiza Compañía de Seguros y Reaseguros contra Compañía Chilena de Navegación Interoceánica S. A. [CCNI] y Agencias Universales Perú S. A. [AGUNSA]), la Sala Permanente de la Corte Suprema de Justicia de la República declaró: (i) infundado el recurso de casación interpuesto por Agencias Universales Perú S. A. (AGUNSA) y (ii) fundado

18 Algunas sentencias y laudos en las que se han invocado las Reglas de Hamburgo se pueden leer en https://uncitral.un.org/es/case_law 
el recurso de casación interpuesto por Compañía Chilena de Navegación Interoceánica S. A., representada por AGUNSA. En los referidos recursos de casación, AGUNSA invocó la infracción del artículo 139, incisos 3 y 5, de la Constitución Política del Perú y CCNI invocó la infracción del artículo 139, inciso 5, de la Constitución Política del Perú; del artículo 1363 del Código Civil, y del artículo 2 del Código de Comercio; en ambos recursos se aludió también al artículo 632 del Código de Comercio. La Sala Permanente de la Corte Suprema de Justicia fundamentó su decisión en el artículo 1, inciso b), y en el artículo 3 de las Reglas de La Haya, referidos al concepto de transporte marítimo y a las obligaciones del porteador en el contrato de transporte marítimo internacional de mercancías, respectivamente.

2. En la Casación 898-2012-Callao (Rímac Internacional Compañía de Seguros y Reaseguros contra CMA CGM Société Anonyme, Trabajos Marítimos S. A. y otros), la Sala Permanente de la Corte Suprema de Justicia de la República declaró infundado el recurso de casación interpuesto por CMA CGM Société Anonyme, Trabajos Marítimos S. A. y otros, en el que estas empresas invocaron la interpretación errónea del artículo 632 del Código de Comercio. Una de las razones fue la aplicación que se efectuó del artículo 3, numerales 2, 3 y 4, de las Reglas de la Haya, relativos al cuidado de las mercancías por parte del porteador, a la emisión del conocimiento de embarque y a la presunción de que el porteador recibió las mercancías en el estado en que se encuentran descritas en el conocimiento de embarque.

3. En la Casación 2563-2009-Callao (Contilatin del Perú S. A. contra Destino dos Navigation Ltd. y Allied Marine Inc.), la Sala Permanente de la Corte Suprema de Justicia de la República declaró infundado el recurso de casación interpuesto por la Agencia Marítima de Barcos S. A., en representación de las demandadas, en el que entre otras cuestiones esta adujo la aplicación indebida de los artículos 600 y 603 del Código de Comercio y 1183 del Código Civil, al señalar que estas normas no regulan la responsabilidad solidaria, sino la mancomunada, y al no haberse interpretado sistemáticamente con el artículo 1, literal a), y el artículo 2 de las Reglas de La Haya, relativos a la definición de porteador y a la responsabilidad del porteador, respectivamente. La razón por la cual la Sala Permanente de la Corte Suprema de Justicia declaró infundado el recurso de casación fue que no corroboró la infracción sustantiva denunciada y coligió que el propietario del buque es responsable conjuntamente con el naviero o transportista de la entrega de las mercancías en perfecto estado.

4. En la Casación 5059-2008-Callao (El Pacífico-Peruano Suiza Compañía de Seguros y Reaseguros contra Compañía Chilena de Navegación Interoceánica [CCNI]), la Sala Permanente de la Corte Suprema de Justicia de la República 
declaró fundado el recurso de casación y se pronunció sobre la inaplicación del artículo 3, incisos 3 y 4, de las Reglas de La Haya, que se refieren a las obligaciones del porteador en la emisión del conocimiento de embarque en la sentencia de segunda instancia emitida por la Segunda Sala Civil de la Corte Superior de Justicia del Callao, ordenando que dicha Sala emita un nuevo pronunciamiento en el que aplique la referida norma de las Reglas de La Haya.

5. En la Casación 4337-2008-Callao (San Fernando S. A. contra Meldrew Marine Ltda. y Centurian Maritime), la Sala Permanente de la Corte Suprema de Justicia de la República declaró infundado el recurso de casación interpuesto por Meldrew Marine Ltda. y Centurian Maritime, en el que estas adujeron la aplicación indebida de los artículos 600 y 603 del Código de Comercio, al no haberse interpretado sistemáticamente con el artículo 1, literal a), de las Reglas de La Haya, relativo a la definición de porteador. Sin embargo, la razón de fondo por la cual la Sala Permanente de la Corte Suprema de Justicia declaró infundado el recurso de casación se debió a la interpretación que se hizo del concepto de avería simple contenido en el artículo 822 del Código de Comercio.

\section{REFLEXIONES FINALES SOBRE EL IMPACTO DE LA DENUNCIA DE LAS REGLAS DE LA HAYA}

El Convenio Internacional para la Unificación de Ciertas Reglas en Materia de Conocimientos de Embarque de 1924, como se mencionó al inicio de este artículo, fue denunciado por el Estado peruano mediante el Decreto Supremo 012-2020-RE, publicado el 12 de mayo del 2020. El último párrafo del artículo 15 de las Reglas de La Haya estipula: "La denuncia producirá efecto únicamente con respecto al Estado que la haya notificado y un año después de haber llegado la notificación a poder del Gobierno belga". La denuncia de las Reglas de La Haya entrará en vigor en el Perú el 1 de abril del 2022. conforme lo señala la adenda a la denuncia de las Reglas de La Haya efectuada por el Perú, publicada por el Gobierno belga el 14 de abril del 2021, la cual se basa en lo dispuesto en el artículo 30 de las Reglas de Hamburgo.

El 26 de febrero del 2021, se publicó el Decreto Supremo 006-2021-RE, a través del cual el Estado peruano adhiere a las Reglas de Hamburgo. De acuerdo con el artículo 2 del citado decreto supremo, que no es muy claro - pues la denuncia de las Reglas de La Haya, como se mencionó antes, se produjo en mayo del 2020-y que alude al párrafo 1 del artículo 31 de las Reglas de Hamburgo:

El Ministerio de Relaciones Exteriores notificará al Gobierno de Bélgica que la denuncia del Perú de la "Convención Internacional para la Unificación de Ciertas Reglas en Materia de Conocimiento de Embarque" adoptada en Bruselas el 25 de agosto de 1924 surtirá efecto para el Perú cuando el Convenio de 1978 entre en vigor para el Perú. 
Las Reglas de Hamburgo que se aplicarán a los contratos de transporte marítimo internacional de mercancías en el Perú, en reemplazo de las Reglas de La Haya, empezarán a regir en el país el 1 de abril del 2022, de acuerdo con lo dispuesto en dicho instrumento internacional y lo señalado en una nota del Ministerio de Relaciones Exteriores del Perú publicada el 9 de mayo del 2021 en la separata "Normas Legales" del diario oficial El Peruano, al pie del texto de las Reglas de Hamburgo, en la que se expresa que este instrumento entrará en vigor el 1 de abril del 2022.

Como hemos visto, la parte medular de las Reglas de La Haya y de todos los convenios internacionales relacionados con el transporte marítimo es la concerniente a la responsabilidad del porteador y la distribución de riesgos y costos entre las partes. En este sentido, históricamente, los dos sectores identificables como partes en los contratos de transporte marítimo: los embarcadores y los navieros, como contrapartes y con intereses antagónicos, sobre todo para soportar los costos por las pérdidas, averías o retraso en la entrega de las mercancías, siempre intentarán atribuir o imputar el mayor peso de la responsabilidad unos a otros.

La denuncia de las Reglas de La Haya -cuestión que en el Perú debió debatirse antes de tomar esa decisión y con la presencia de todos los interesados en el transporte marítimo, incluida la academia - se dio precedida de una insistente presión por el lado de los generadores de carga, que aducen desde hace algunos años la existencia de ciertos cobros por los proveedores de servicios de transporte y sus auxiliares independientes, que no se condicen con la realidad; denuncia que es rechazada por las líneas navieras y por los agentes generales y marítimos.

La crisis generada por la pandemia del COVID-19, iniciada en marzo del 2020, provocó la adopción de normas internas para facilitar el tráfico de las cadenas logísticas, así como profundizar la digitalización de procedimientos privados - incluida la emisión de conocimientos de embarque-y públicos ligados al transporte. Entre otras normas, se aprobó una que altera el periodo de responsabilidad del porteador contemplado en las Reglas de La Haya; me refiero al párrafo 13.3 del Decreto Legislativo 1492, que estipula: “La obligación del transportista internacional culmina con la entrega de la mercancía en el terminal o lugar dispuesto por el dueño, consignatario o consignante en el documento aduanero correspondiente". Esta norma, que no habla de responsabilidad civil, pero sí alude a la extensión de la "obligación del transportista internacional", no guarda concordancia con las Reglas de La Haya, cuyo periodo de responsabilidad, como se ha indicado, es de "gancho a gancho".

Considero que esas son las razones por las que el Gobierno peruano decidió denunciar las Reglas de La Haya. Es cierto que la denuncia de un convenio internacional, en especial de este instrumento de tanta importancia en el tráfico marítimo internacional, requiere de profundos análisis, en particular respecto al impacto que podría tener en 
los costos de transacción que ello conlleva, incluidos los relacionados con los fletes, los seguros y la seguridad jurídica. Como es dato conocido, son los consumidores los que soportan finalmente los costos derivados del transporte marítimo de mercancías.

Como fue recordado anteriormente, en el Proyecto de Ley de Navegación y Comercio Marítimo que presentamos en 1999 los que integramos un grupo de trabajo creado en el marco de la Ley 26595, se formuló la derogación del libro III del Código de Comercio de 1902 y la adhesión del Perú a las Reglas de Hamburgo. Este proyecto de ley fue muy expuesto y debatido en varios eventos realizados entre 1997 y el 2000, y el texto ha sido objeto de análisis en varias publicaciones especializadas en el Perú y en el extranjero.

Un importante sector de la doctrina maritimista, como hemos visto, resalta la superioridad técnica de las Reglas de Hamburgo frente a las Reglas de La Haya. Las Reglas de Hamburgo son afines al sistema continental, y contienen un régimen de responsabilidad que distribuye más equilibradamente los riesgos y costos del transporte marítimo. Precisamente esta asignación más equitativa de riesgos y costos entre las partes no es aceptada por las líneas navieras, básicamente porque se eliminan algunos eximentes de responsabilidad que pueden ser invocados por los porteadores y porque se elevan los montos de la deuda resarcitoria.

La propuesta que hemos reiterado en eventos y notas publicadas es que se conforme un grupo de trabajo integrado por expertos alejados de cualquier interés que no sea el más conveniente para el país, que se encargue de redactar un Proyecto de Ley de Navegación y Comercio Marítimo, cuya fuente principal podría ser el citado proyecto de 1999. Como señalé antes, las Reglas de Hamburgo están vigentes en Chile hace más de treinta años y es conocido el éxito que han tenido las empresas navieras chilenas en Sudamérica y en el mundo. La singladura recomendable sería aprobar una Ley de Navegación y Comercio Marítimo alineada con la adhesión a las Reglas de Hamburgo, y siguiendo la fórmula legal recogida en la disposición final primera de la Ley de Navegación Marítima de España, Ley 14/2014, una vez que las Reglas de Rotterdam entren en vigor, adherirnos a estas e incorporar sus normas a la ley nacional.

\section{REFERENCIAS}

Alzueta, A. M. (1977). Responsabilidad limitada en el derecho de la navegación. Plus Ultra.

Arroyo, I. (1993). Estudios de derecho marítimo (vol. I). Librería Bosch.

Arroyo, I. (2001). Curso de derecho marítimo. J. M. Bosch.

Berlingieri, F. (1983). La responsabilidad del transportador de mercadería por agua. En Seminario de Buenos Aires organizado por la Asociación Argentina de Derecho Marítimo. Dott. A. Giuffré Editore. 
Berlingieri, F. (2009). A Comparative Analysis of the Hague-Visby Rules, Hamburg Rules and Rotterdam Rules. https://www.uncitral.org/pdf/english/workinggroups/wg_3/ Berlingieri_paper_comparing_RR_Hamb_HVR.pdf

Berlingieri, F. (2012). La disciplina de las obligaciones del porteador y su responsabilidad. En M. Alba Fernández y R. Illescas Ortiz (Dirs.), Las Reglas de Rotterdam: una nueva era en el derecho uniforme del transporte (pp. 53-100). Dykinson.

Blas Simone, O. (1980). Las Reglas de Hamburgo. Novum Forum.

Cabanellas, G. (1986). Diccionario enciclopédico de derecho usual (t. VII). Heliasta.

Comisión Económica para América Latina y el Caribe. (2020). La calma antes de la tormenta: comportamiento del movimiento de contenedores en los puertos de América Latina y el Caribe en 2019 y de los principales puertos durante los primeros meses de 2020. https://www.cepal.org/sites/default/files/news/files/2020_ informe_portuario_2019_v.pdf

Cornejo Fuller, E. (2003). Derecho marítimo chileno. Explicaciones sobre el libro III del Código de Comercio: de la navegación y el comercio marítimo. Ediciones Universitarias de Valparaíso.

Chami, D. E. (2010). Manual de derecho de la navegación. Abeledo Perrot.

El Anteproyecto de la Ley General de la Navegación y del Comercio Marítimos. (1999). En Comisión de Reforma de Códigos del Congreso de la República (Legislatura 19981999) (t. II). Congreso de la República del Perú.

Emparanza Sobejano, A., y Martín Osante, J. M. (2010). El transporte marítimo (II). Contrato de transporte marítimo de mercancías en régimen de conocimiento de embarque. En F. Martínez Sanz (Dir.), Manual de derecho del transporte (pp. 113-137). Marcial Pons.

Gabaldón García, J. L., y Ruiz Soroa, J. M. (2006). Manual de derecho de la navegación marítima (3. ${ }^{\mathrm{a}}$ ed.). Marcial Pons.

González-Lebrero, R. (1998). Curso de derecho de la navegación. Servicio Central de Publicaciones del Gobierno Vasco.

Illescas Ortiz, R. (2010). Las claves de las Reglas de Rotterdam. En J. C. Sáenz García de Albizu, F. Oleo Banet y A. Martínez Flórez (Coords.), Estudios de derecho mercantil en memoria del profesor Aníbal Sánchez Andrés (pp. 1815-1827). Civitas; Thomson Reuters.

Martín Osante, J. M. (2010). Responsabilidad del porteador por pérdida, daño o retraso en las Reglas de Rotterdam. En A. Emparanza Sobejano (Dir.), Las Reglas de Rotterdam (la regulación del contrato de transporte internacional de mercancías por mar) (pp. 253-284). Marcial Pons. 
Pejovés Macedo, J. A. (1999a). La reforma del derecho marítimo peruano. Anuario de Derecho Marítimo, 16, 321-336.

Pejovés Macedo, J. A. (1999b). La reforma del derecho marítimo peruano. En El Código Civil y el Código de Comercio: proceso de reforma legislativa. Pontificia Universidad Católica del Perú.

Pejovés Macedo, J. A. (2006). El sistema de responsabilidad aplicable al porteador en el transporte marítimo de mercancías y su tratamiento en el ordenamiento marítimo peruano. Anuario de Derecho Marítimo, 23, 167-186.

Pejovés Macedo, J. A. (2007). Derecho marítimo. 25 ensayos (transporte marítimo, multimodal y puertos). Cultural Cuzco.

Pejovés Macedo, J. A. (2008). ¿Es necesario modernizar el derecho marítimo peruano? (La derogación del libro III del Código de Comercio peruano de 1902, la sustitución de las Reglas de La Haya de 1924, y la aprobación de una ley de navegación y comercio marítimo). lus et Praxis, 38-39, 269-328.

Pejovés Macedo, J. A. (2019). Diálogo entre el derecho civil y el derecho marítimo (buques, registro, responsabilidad civil del naviero/porteador, testamento marítimo, infraestructuras portuarias). En Congreso Internacional de Derecho Civil (vol. II). Instituto Pacífico.

Pinto-Bazurco, E. (1997). Diccionario de relaciones internacionales (diplomático, económico y jurídico). Universidad de Lima, Fondo Editorial.

Ray, J. D. (noviembre de 1978). La Convención de Bruselas de 1924 y las Reglas de Hamburgo de 1978. XV Asamblea General Ordinaria y Reunión de Directorio N. ${ }^{\circ} 46$ de la Asociación Latinoamericana de Armadores (ALAMAR), Viña del Mar, Chile.

Ray, J. D. (1994a). Derecho de la navegación (t. II). Abeledo Perrot.

Ray, J. D. (1994b). Responsabilidad de los porteadores en las Convenciones Internacionales sobre Conocimientos de Embarque. Anticipo de Anales. Academia de Derecho y Ciencias Sociales de Buenos Aires, Año XXXVIII, Segunda Época(31), 13.

Ray, J. D. (1996). Distintos enfoques sobre la responsabilidad en el derecho. Anticipo de Anales. Academia de Derecho y Ciencias Sociales de Buenos Aires, Año XL, Segunda Época(33), 25-26.

Ripert, G. (1954). Derecho marítimo (P. G. San Martín, Trad.). Tipográfica Editora Argentina.

Sánchez Calero, F. (1981). Las Reglas de Hamburgo sobre el contrato de transporte marítimo de mercancías. Una valoración crítica. Comité de Derecho Marítimo de Barcelona.

Sánchez Calero, F. (2000). El contrato de transporte marítimo de mercancías (Reglas de La Haya-Visby). Aranzadi. 
